\title{
0795 PARTICIPATION AND INJURIES IN ORGANISED SPORTS IN GERMANY: A LONGITUDINAL STUDY COVERING THE YEARS 1987-2009
}

C Klein, P Luig, D Schulz, T Henke* Correspondence: Department of Sports Medicine, Ruhr-University Bochum, Overbergstr. 19, Bochum, 44780, Germany

\subsection{6/ip.2010.029215.795}

Following the Resolution on Sport for All: injuries and their prevention in 1986 the Department of Sports Medicine of the Ruhr-University Bochum and the ARAG Sports Insurance established a database of sports accidents. For over 20 years this cooperation has intended to reveal focal points of accidents on the basis of statistically verified and representative data. Furthermore, the development of preventive approaches with targeted measures suited to specific sports has always been a pivotal aim. Athletes that have reported a sports accident to the sports insurance company have been asked to fill in a questionnaire relating to the course of the accident, the injury and its treatment as well as the amount of organised and unorganised sporting activities. The response rate is approximately $50 \%$. The collected data covers more than 180000 sports accidents between 1987 and 2009. Thus it is one of the largest sports injury databases in Europe.

The aim of this study is to consider the progress of the accidents and to highlight the main changes of sports injuries in comparison with the number of participants within German sports associations, finally leading to the elaboration of prevention measures. The focus is on sports with the highest absolute number of injuries. In fact football is the leading sport in Germany concerning the number of injuries and participants. It is outstanding that $75 \%$ of all organised sports injuries are registered in football, handball, basketball and volleyball, although only $30 \%$ of all sports club members are organised within these sports. 